\title{
Energy access during and post-COVID-19 pandemic in sub-Saharan countries: the case of Ethiopia
}

\author{
Yohannes Biru Aemro, ${ }^{1,}$. Pedro Moura2 (D) Aníbal T. de Almeida²
}

Received: 5 July 2020 / Accepted: 22 December 2021 / Published online: 4 January 2022

(c) The Author(s), under exclusive licence to Springer Nature B.V. 2022

\begin{abstract}
The global COVID-19 pandemic causes hundreds of thousands of deaths and has created a catastrophic economic and health crisis around the World. Transportation, manufacturing industries, business and people's movement came to almost a halt and sharp oil and gas prices reduction were observed. The impact of the pandemic for sub-Saharan countries like Ethiopia, which was already struggling with many economic and social welfare problems, is more evident than in other wealthy nations around the World. In Ethiopia, the general energy access rate is $44 \%$ and in healthcare facilities is only about $10 \%$. Therefore, the response for the COVID-19 pandemic is challenging, since activities such as information sharing, communication with health centers, diagnosis and medical treatment require electricity access. This paper aims to assess the impact of the pandemic on energy access plans during and post-pandemic. The paper analyzed, the status of the current COVID-19 outbreak in Ethiopia, the energy access situation in health facilities, and the impacts of COVID-19 on energy access during and post-pandemic periods. Data related to the universal energy access plan of Ethiopia, the impact of energy access on healthcare services and the impact of the pandemic were reviewed for the assessment. The analysis indicates that the impact of the COVID-19 pandemic in Ethiopian healthcare facilities and on the overall universal energy access plan is immense and to minimize the global impact short and longterm policy responses are identified and urgently recommended. Furthermore, powering healthcare facilities with microgrids composed of solar panels and battery storage systems could be one cost-effective and sustainable solution for the speedy and effective response of the pandemic challenges.
\end{abstract}

Keywords COVID-19 $\cdot$ Ethiopia $\cdot$ Energy access $\cdot$ Healthcare facilities $\cdot$ Indoor air pollution $\cdot$ Policy responses $\cdot$ Microgrids

Yohannes Biru Aemro

yonimail.05@gmail.com; yohannes.aemro@isr.uc.pt

Pedro Moura

pmoura@isr.uc.pt

Aníbal T. de Almeida

adealmeida@isr.uc.pt

1 Energy for Sustainability Initiative, University of Coimbra, Polo II, 3030-290 Coimbra, Portugal

2 Department of Electrical and Computer Engineering, Institute of Systems and Robotics, University of Coimbra, Polo II, 3030-290 Coimbra, Portugal 


\section{Introduction}

The World is facing an unprecedented crisis, which is considered as one of the greatest challenges the world is facing since World War II (Gautam, 2020) due to the Novel Coronavirus (COVID-19) pandemic. It requires coordinated efforts from each and every stakeholder, including individuals, communities and civil organizations, governments, international agencies like World Health Organization (WHO) at every level and Non-Governmental Organizations (NGOs). The World economy and health sectors are experiencing historic and extraordinary shocks, as the pandemic triggers a number of shocks simultaneously including energy supply, food supply, economic activity and financial losses. Like other countries in the World, Ethiopia is also experiencing those challenges to a greater extent due to low socio-economic development and lack of services with adequate quality. The Ethiopian government is taking different actions to control the pandemic through partial and full business closures, as well as allowing government workers to work from home. However, the efforts have been leading to a huge decline in economic activities (EEA, 2020).

After the first case reported on March 13, 2020, in the first 2 months (from March 13 to May 15, 2020), the number of people infected by COVID-19 was about 250. However, this number increased by tenfold in the third month (from May 15, 2020, to June 15, 2020) (Tadesse, 2020). This implies that the hospitals and all healthcare facilities should be on alert with full capacity and improve the level of services. On the other hand, studies have shown that communities with low economic levels are more vulnerable to increased rates of chronic illness from the COVID-19 which is further complicated by socio-economic sufferings (EEA, 2020). Even though on average the economy has been increasing for the last decade by $10.1 \%$ (fastest-growing economies in Africa, as well as in the world), if the current trend of the spread of COVID-19 pandemic continues, the gains of the rapid economic growth will be wiped off, and the poverty level will increase from the number where it is now (26 million people lives in absolute poverty), and other service sectors like education, health will be at risk.

On the other hand, even if the quality of services remains a huge challenge, there are positive improvements recorded in the access to primary education and health in the last decade. Besides, about $56 \%$ of the population lacks access to electricity, $93 \%$ lack access to clean cooking, $58 \%$ of the population lack access to clean water, $89 \%$ live without safe toilets and 48 million people live further than $2 \mathrm{~km}$ from all-weather roads (Alemu, 2020). Additionally, about $90 \%$ of healthcare facilities do not have access to any type of modern energy system (MoWIE, 2019), which seriously affects the type of services that they are able to offer.

The COVID-19 pandemic has also caused a serious impact on the global energy sector, in which the oil prices and the demand for oil unexpectedly decreased (IEA, 2020a, 2020b, 2020c, 2020d, 2020e). The impact on developing countries including Ethiopia where most of the population lives without access to modern energy services is more relevant. Women and children are the most affected by the lack of access to modern energy services, since they live either in crowded cities or in rural areas. They are also the most responsible population sector in developing countries for the collection of solid biomass fuels and cooking activities. In the period of a pandemic, energy access is as critical as ever for households and businesses, but particularly in the healthcare infrastructure. Additionally, the ability of doctors and health workers to treat infected populations also depends on access to sufficient, uninterrupted, reliable electricity supply for the healthcare facilities and medical 
equipment. Furthermore, the impact of COVID-19 is not limited to the energy and economic sector, rather it can also impact the achievement of all the sustainable development goals by 2030. For instance, if the pandemic is not dealt with in the short term (e.g., end of 2022), the poverty level could raise in most developing countries. As a result, Sustainable Development Goal 1(SDG 1) (No poverty) and Sustainable Development Goal 2 (SDG 2) (Zero hunger) are at major risk of not being achieved (Leal Filho et al., 2020).

Even if the Ethiopian universal electrification plan by 2025 includes the electrification of healthcare systems as one core issue, the efficient response to the pandemic requires an urgent electricity supply of the healthcare systems. To address such an issue, it is necessary to analyze the impact of COVID-19 on the energy access situation, not only during but also post-pandemic. This study aims to address this issue and gives insights for the Ethiopian energy sector, as well as different stakeholders including policymakers that are working on solving Ethiopian energy access problems such as investors, private sector development partners and NGOs.

Therefore, this paper assesses the energy access situation in Ethiopia as well as in the healthcare facilities to understand how the country's response to the COVID-19 pandemic could be affected due to lack of energy access. The objective of the study is to present the link between energy access and healthcare services by assessing recent literature and situations that happened during the pandemic and to show direction for policymakers and government bodies to consider such incidence in the plan for energy access and health facilities. Therefore, this study thoroughly assessed the energy access plan of Ethiopia and what will be the impact of the Pandemic to achieve these goals, as well as the directions to impede the severe impact of the pandemic in the country are identified. Those directions also apply to countries of sub-Saharan Africa that are in a similar situation like Ethiopia in many aspects including economic development and energy access. For the analysis, reports about the impact on energy markets due to the pandemic, daily briefings on the status of the pandemic in Ethiopia and globally, different articles discussing the link between energy access and healthcare services as well as the impact of lack of energy access on the response of the pandemic were considered. The assessed data and associated discussion are focused only on the Ethiopian context. Hence, the objective of this paper is to assess the impact of COVID-19 on the Ethiopian energy access situation and energy access plans. Furthermore, it draws the attention of the government, policymakers, NGOs, donors, finance sectors and researchers to consider the energy access situations in Ethiopia at the time of the pandemic and promote a fast improvement in a post-COVID-19 pandemic.

The study followed a qualitative research approach that gives an opportunity to answer multiple research questions identified during this study. The study examined the situation of the COVID-19 pandemic in the Ethiopian context and its impacts on Energy access in Ethiopia and in countries with similar situations, like Ethiopia. Literature was reviewed from journals, policy briefs, press releases, and different sources. Data were collected by inclusion and exclusion criteria from published articles specific to COVID-19. Data from the Federal Ministry of Health of Ethiopia, Ethiopian Public Health Institute, Federal Ministry of Water, Irrigation and Electricity Federal Ministry of Finance, government press release, media briefs, unpublished reports, and relevant COVID-19 articles published since January 2020 were collected and assessed. Data were collected from Google Scholar and other sources using simple search (blind searching), systematic search (identifying, selecting, and synthesizing published resources on COVID-19 and energy access), COVID-19 recovery plans, and thread searching technique (using references listed in relevant publications leads to other relevant publications). Finally, data were synthesized and analyzed using the qualitatively thematic analysis method. 
The remainder of the paper is organized as follows. Section 2 presents the background information about Ethiopia and the global COVID-19 outbreak as well as the Ethiopian status. Section 3 presents the energy services access situation in the country and health facilities. In Sect. 4, the discussion about the impact of COVID-19 on the actual and planned energy access is presented and in Sect. 5, the summary of the findings of the study and concluding remarks, as well as the policy responses to address the impact are discussed.

\section{Ethiopia and COVID-19 outbreak}

\subsection{Ethiopia: general information}

Ethiopia is a country located in Easter African commonly called the horn Africa which shares borders with Eritrea, Djibouti, Somalia, Kenya, South Sudan and Sudan. Currently, the population is above 114 million which makes the country the second-most populous country in the African continent with about $80 \%$ of the total population is located in rural areas (worldometers, 2020). As per the Ministry of Health of Ethiopia prediction, about 28 million people could be infected by the COVID 19, considering that all urban and $50 \%$ of the rural dwellers are at risk (wazemaradio, 2020).

The government of Ethiopia is taking different measures to minimize the risk of the pandemic and recommends that people exercise the preventive measures recommended by the World Health Organization (WHO, 2020a, 2020b). The recommendations are washing hands frequently using soap or sanitizer, social distancing, wearing masks (everyone going out should have it), getting up-to-date information about the status of the pandemic from reliable sources (in the case of Ethiopia, the Ministry of Health and Ethiopian Public Health Institute). Furthermore, other measures include self-monitoring, social distancing and isolation of vulnerable areas, isolation in isolation centers prepared by the government, avoiding public gatherings in religious institutions and cultural centers, ban nightclubs and bars. However, there are critical factors that greatly influence the relevance and feasibility of such measures including the level of economic and human development as well as the welfare of the community and the country. On the other hand, poverty, access to basic services and facilities, social structure and demography are some of the challenging factors which could increase the spread of the virus, as well as they are fundamental to understanding the vulnerability to the pandemic. Figure 1 presents the basic services access and welfare situation in Ethiopia for selected indicators.

As depicted in Fig. 1, the large majority of the Ethiopian population do not have access to basic services, such as clean water and energy services and therefore the country was already unable to satisfy the basic needs of the people even before the pandemic. At aggregated level only $6 \%$ have access to washing water; only $62 \%$ have access to safe drinking water; about $19 \%$ face problems of food shortage, and about $22 \%$ of the entire population is living in extreme poverty conditions.

\subsection{COVID-19 outbreak: global and Ethiopian status}

After the first case reported to the World Health Organization (WHO) from Wuhan Town, Hubei Province, China at the end of December 2019, the Novel Coronavirus (COVID19), the outbreak has grown into a pandemic (Mulugeta \& Jalata, 2020). Even if the virus started in China and was the first country to suffer from the pandemic, as of July 14, 2021, 


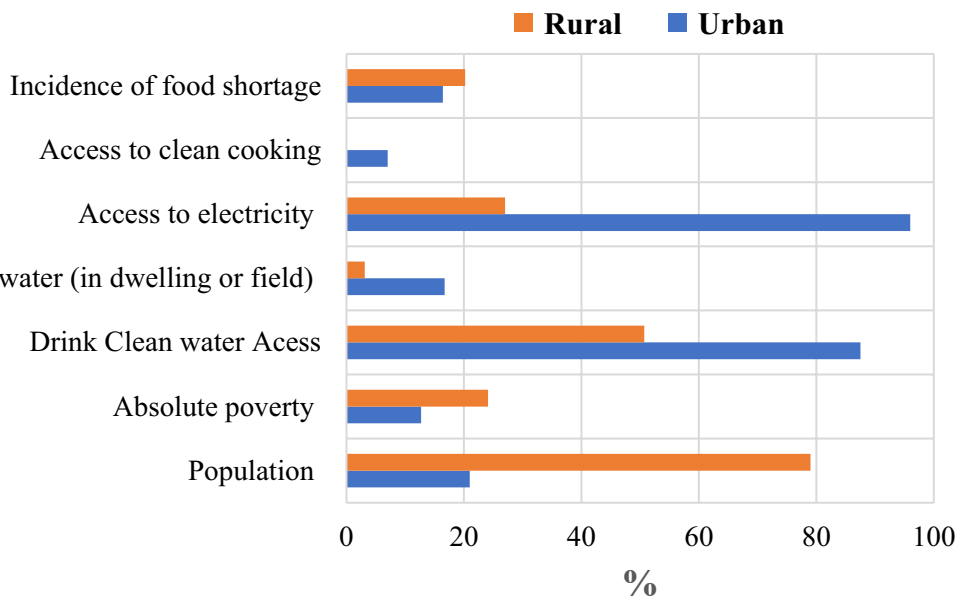

Fig. 1 Basic service and Welfare situation in Ethiopia for selected indicators (source: EEA (2020), Ministry of Health and Ministry of water, irrigation and Energy of Ethiopia)

it has already spread over 215 countries around the globe, as well as the global community is suffering from the whole impact of the health crisis.

Though with vaccine developments and people getting vaccinated in most developed countries, there are still new cases and deaths reported with a high number in countries like India, Brazil, Ethiopia and others day by day. According to the Johns Hopkins University (JHU) resource center report, as of July 23, 2021, Worldwide, there are about 193.2 million confirmed cases of COVID-19 in more than 215 countries/territories. including Ethiopia where 4,143,105 people died and about 3.8 billion vaccine doses were administered. Like other countries, the spread of COVID-19 in Ethiopia is also increasing as shown in Fig. 2. Since the first case was reported on March 13, 2020, a total of 278,233 cases, 4365 deaths and about 262,750 people are recovered. As of July 14, 2021 the country administered about 2,155,657 vaccine doses.

Although the government of Ethiopia is implementing different kinds of measures to control the spread of the virus, the traditional way of life of the people is the main challenge that escalates the spread of the virus in an unprecedented way. The lack of organized systems, overcrowded public transportation and market places, hand-to-mouth living standards for the majority of the population, greeting habits, congested living rooms, and unfavorable workplaces were feared to worsen the situation in Ethiopia. Moreover, the traditional coffee ceremony, meal gathering (it is a tradition to eat together in a family as well as with neighbors), group-based shisha smoking and chat/khat chewing, crowds of street vendors and religious congregations are feared to contribute to the spread of the virus, particularly in urban areas. On the other hand, traditional farming and harvesting habits (including working in groups and working 1 day in one farmer's farm and the other day in another farmer's farm) could lead to the virus spread in rural and remote areas, unless proper and strict awareness creation and measures are taken by every stakeholder and responsible body before it is too late.

The country was under a state of emergency since mid-April, 2020 which was planned to stay for 5 months. Like other countries around the World, all business enterprises, education institutions, informal and subsistence businesses and government offices are profoundly 


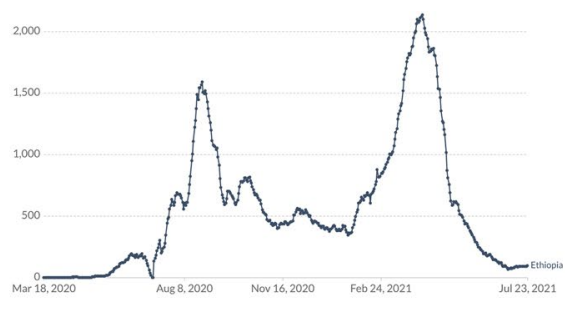

(a) Daily new confirmed COVID-19 cases

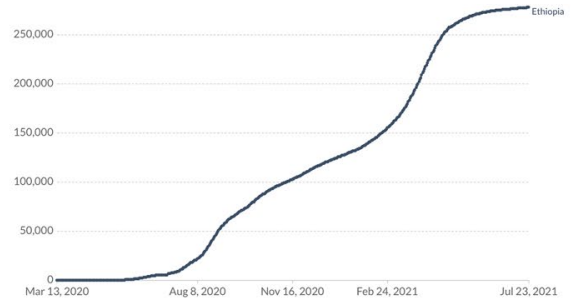

(b) Cumulative confirmed COVID-19 cases

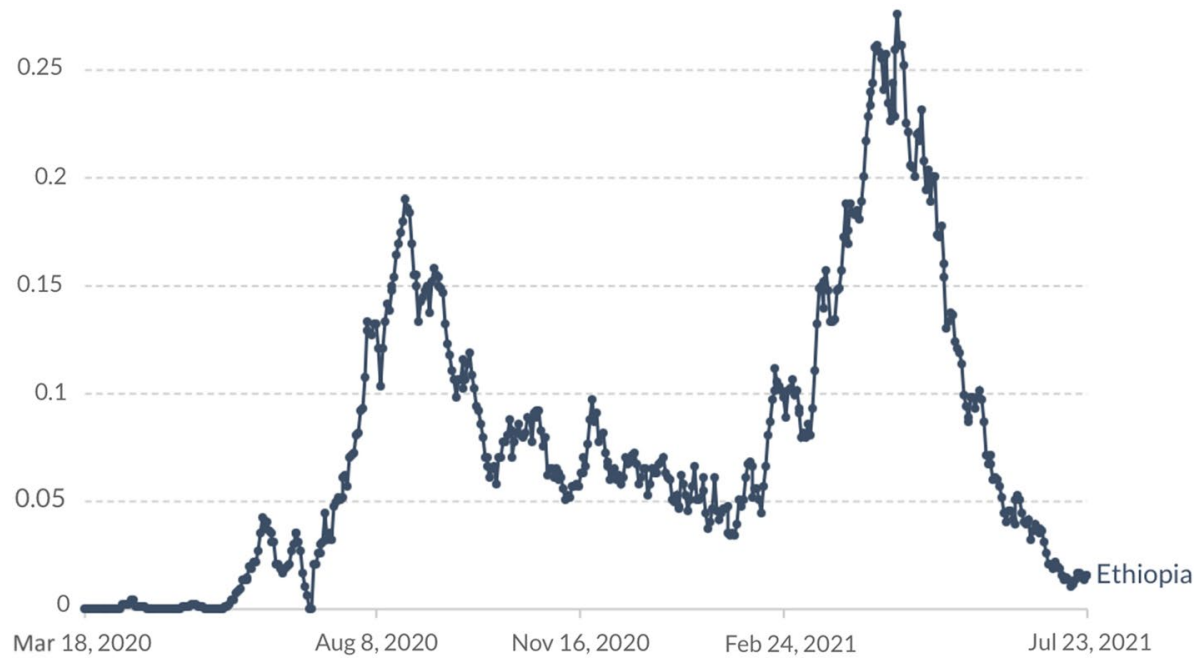

(c) Daily new confirmed COVID-19 deaths per million people

Fig. 2 Daily confirmed cases (a), total confirmed cases (b), and daily confirmed deaths per million people (c) in Ethiopia as of July 23, 2021 (Johns Hopkins University COVID-19 dashboard)

impacted by the pandemic. The majority of the existing about 7.5 million employees in government offices, NGOs, international organizations and private companies are forced to stay home or work from home. Vulnerable people working in several informal business sectors including street vending, manufacturing, construction, mining/quarrying, wholesale and retail trade are also impacted. All these activities with no doubt will exacerbate the socio-economic and food insecurity problems in the country. As such calling for wide-ranging thorough planning and proper management to buffer the challenges is necessary. On the other hand, people with large families and living in congested areas could increase the outbreak if special precautions are not taking place. 


\section{Energy access and health facilities}

\subsection{Access to electricity}

Access to energy services is required for better quality healthcare services, since many treatments require electricity and without it, patients cannot get optimal services such as diagnostics and treatment. Most of the operating procedures in healthcare facilities need energy for ventilation, temperature and water control/purification, lighting and medical equipment operations. The link between healthcare service quality and energy accessibility is different for underdeveloped, developing and developed countries. In developed countries, healthcare services problems are not related to access to energy rather they are related to management and availability of enough human resources like personal protective equipment (PPE), access to new and advanced technologies and equipment as well as fast increasing budgets and energy efficiency measures. Whereas, in developing countries like Ethiopia, access to reliable, affordable and clean energy for basic services is the main challenge (Andrea Franco, 2017). On the other hand, the improvement of energy services is becoming critical for the country's socio-economic development including economic progress, key climate, environment, health, employment, and food security change factor (Muhammad Yousaf Razaa, 2021).

The electricity access rate in Ethiopia is about $44 \%$, where $33 \%$ of the total is through grid connections and $11 \%$ is through off-grid connections. As presented in Fig. 3, electricity access varies by a great margin across the country. Overall, in urban areas, about $95 \%$ (the capital city Addis Ababa accounts for 99.9\%) of the population have access to electricity through grid connections, whereas only $27 \%$ of the rural population (more than $80 \%$ of the population of the country located in rural areas) gets access to electricity services through only off-grid solutions. The access in deep rural areas is at the lowest rate which is about 5\%; followed by rural areas, with about $5-10 \%$ of access; and then peri-urban areas, with about $20 \%$ of access (MoWIE, 2019).

In relation to the electricity consumption per capita, the average electricity consumption per capita is about $52 \mathrm{kWh} /$ year which is very low compared with developed countries, for instance with 12,235 kWh/year in the USA (Ourworldindata, 2020). Figure 4 presents the share of electricity generation in Ethiopia, which indicates that hydropower provides almost $90 \%$ of the electricity in the country and about $8 \%$ is provided by other renewable energy sources including solar, wind, geothermal, biomass and others. Diesel

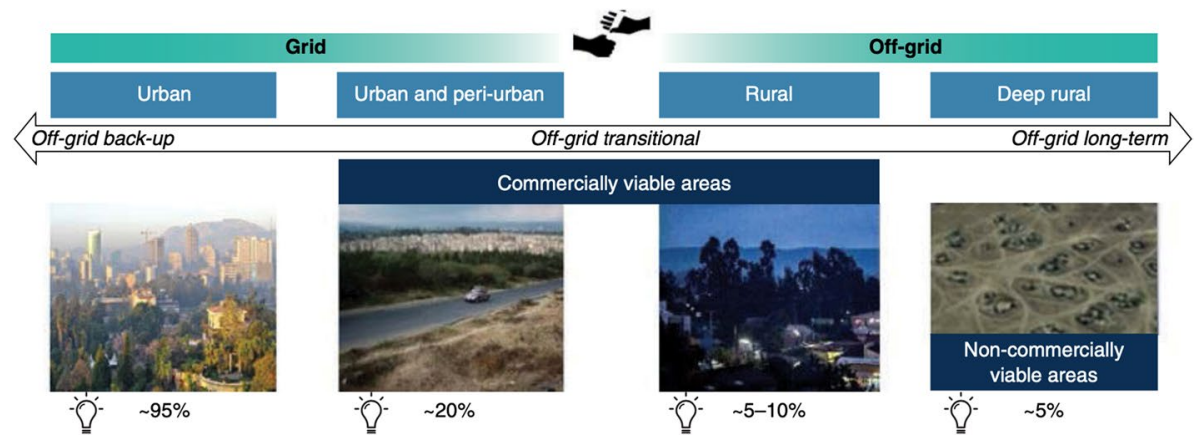

Fig. 3 Access challenge, by geography (MoWIE, 2019) 
Fig. 4 Share of electricity generation in Ethiopia (IEA, 2020a, 2020b, 2020c, 2020d, 2020e)

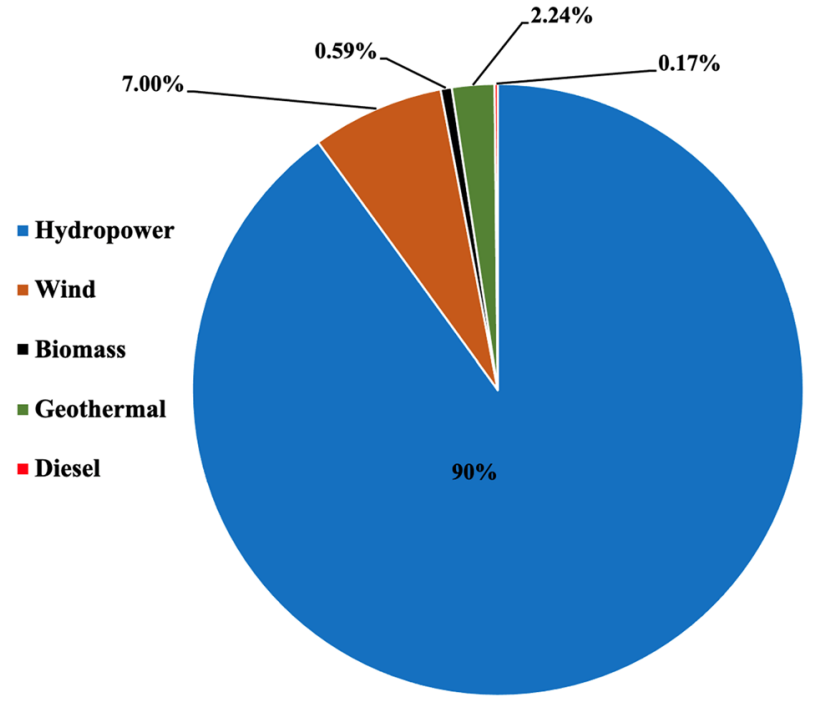

power plants contribute with a small portion $(\sim 2 \%)$ and energy from biomass, such as wood, crop waste and animal dung has been serving the majority of the population for household purposes, particularly for cooking (IEA, 2020a, 2020b, 2020c, 2020d, 2020e).

On the other hand, Ethiopia is rich in IndIgenous energy sources with high exploitable theoretical potential. Table 1 presents the theoretical potential and exploited percentage of different renewable energy resources of Ethiopia. Hydropower has a theoretical potential of about 45,000 MW, but only less than $10 \%$ of the total potential is harnessed so far. In 2015, Ethiopia became one of the largest power producers in Sub-Sahara Africa when Gilgel Gibe III dam project was inaugurated with a generation capacity of 1870 MW (Issa, 2016). By now, the country has an installed capacity of more than 4200 MW from hydropower and could reach up to 10,000 MW when ongoing projects are finalized [15]. In line with the average increase in the electrical demand of Ethiopia by $30 \%$ annually, several cities have been electrified in the last 14-15 years (Beyene et al., 2018).

Table 1 Theoretical potential and exploited energy resources of Ethiopia (MoWIE, 2019)

\begin{tabular}{lllc}
\hline Resource & Unit & Theoretical potential & Exploited (\%) \\
\hline Hydropower & MW & 45,000 & $<10$ \\
Solar/day & $\mathrm{kWh} / \mathrm{m}^{2}$ & Avg. 5.5 & $<1$ \\
Wind power & $\mathrm{GW}$ & 1350 & $<1$ \\
Wind speed & $\mathrm{m} / \mathrm{s}$ & 6.5 & $<1$ \\
Geothermal & MW & 7000 & 50 \\
Wood & Million tons & 1120 & 30 \\
Agricultural wastes & Million tons & $15-20$ & 0 \\
Natural gas & Billion m $\mathrm{m}^{3}$ & 113 & 0 \\
Coal & Million tons & 300 & 0 \\
Oil shale & Million tons & 253 & \\
\hline
\end{tabular}


The electricity generation of Ethiopia currently depends on locally available renewable energy resources, which is considered as cost-effective and environmentally friendly energy solutions compared with imported expensive energy resources (Raza, 2020). For instance, the current installed electricity generating plants consist of eight wind farms, one geothermal power plant, 13 hydropower plants, one biomass power plant and some diesel power plants, as presented in Table 2. Additionally, as clearly indicated in Table 2, more renewable energy resources such as solar and wind are going to be commissioned in a near future. Due to the emission of greenhouse gases, shortage of fossil fuels, as well as costs, the use of fossil fuel-based power generation is becoming less attractive (Cassia et al., 2018). However, the Ethiopian energy policy is directed to the use of carbon-neutral technologies, i.e., renewable energy technologies.

Table 2 Installed and under development capacity of power plants in Ethiopia (Besha et al., 2020)

\begin{tabular}{|c|c|c|c|}
\hline Power plants & Type & Operational since & Capacity (MW) \\
\hline Aba Samuel & Hydropower & 1932 & 6.6 \\
\hline Koka & Hydropower & 1960 & 43.2 \\
\hline Tis ABay I & Hydropower & 1964 & 11.4 \\
\hline Awash II & Hydropower & 1966 & 32 \\
\hline Awash III & Hydropower & 1971 & 32 \\
\hline Fincha & Hydropower & $1973 / 2003$ & 134 \\
\hline Melka Wakena & Hydropower & 1998 & 153 \\
\hline Tis Abay II & Hydropower & 2001 & 73 \\
\hline Gilgel Gibe I & Hydropower & 2004 & 184 \\
\hline Tekeze & Hydropower & 2009 & 300 \\
\hline Gilgel Gibe II & Hydropower & 2010 & 420 \\
\hline Beles & Hydropower & 2010 & 460 \\
\hline Fincha Amerti Neshi & Hydropower & 2011 & 97 \\
\hline Gilgel Gibe III & Hydropower & 2015 & 1870 \\
\hline GERD & Hydropower & Expected in 2022 & 6000 \\
\hline Alutto Langano & Geothermal & 1999 & 7.3 \\
\hline Adama I & Wind & 2010 & 51 \\
\hline Ashegoda & Wind & 2012 & 120 \\
\hline Adama II & Wind & 2015 & 153 \\
\hline Ayisha & Wind & Under development & 300 \\
\hline Debre Birhan & Wind & Under development & 100 \\
\hline Asela & Wind & Under development & 100 \\
\hline Mesebo Harena & Wind & Under development & 42 \\
\hline Galema I & Wind & Under development & 250 \\
\hline Metahara & Solar & Under development & 100 \\
\hline Gad and Dicheto & Solar & Under development & 250 \\
\hline Tigray & Solar & Under development & 500 \\
\hline Kaliti & Diesel & 2004 & 14 \\
\hline Dire Dawa & Diesel & 2004 & 38 \\
\hline Awash 7 kilo & Diesel & 2004 & 35 \\
\hline
\end{tabular}




\subsection{Access to clean cooking}

According to recent studies, with the spread of COVID-19, people exposed to air pollution are more affected by the virus than people living in more clean air (Carrington, 2020) (Edoardo Conticini, 2020). Figure 5 presents the fuels and technologies used for cooking in Ethiopia and it is dominated by solid biomass fuels with 84\% (IEA, 2020a, 2020b, 2020c, 2020d, 2020e), provided that traditional cooking technologies including three-stone open fire are the dominant technology which accounts for $63.3 \%$ of the total. At an aggregate level, more than $90 \%$ of the population (more than 105 million) uses biomass fuels.

The penetration of clean fuels and technologies is only $7 \%$, which is very low, provided that the health and energy-saving benefits of clean fuels and technologies are still at a low rate (Padam, et al., 2018). This situation is a warning sign, where most of the people, in particular women and children, are exposed to air pollution since they are mostly responsible for cooking and gathering of cooking fuels. It is known that people exposed to household air pollution from cooking are mostly affected by respiratory infections such as pneumonia and aggravate respiratory illnesses like asthma and die from it-which may, in turn, lead to poorer outcomes after a COVID-19 infection (Carrington, 2020).

In Ethiopia, the use of solid biomass fuels and low efficient traditional cooking is the main environmental risk factor behind the recorded premature deaths and above 65,000 premature deaths were caused by household air pollution, as well as over 3.1 million disability-adjusted life-years per year are caused by household air pollution (Beyene, 2018). Furthermore, the families in Ethiopia spent an average of $2 \mathrm{~h}$ per day collecting cooking fuels (Kammila et al., 2014), which could increase the possibility of exposure to the virus.

\subsection{Energy access in health facilities}

Like other services, healthcare facilities also lack access to energy even for basic services, such as lighting, heating and the powering of medical equipment. This limits diagnostic capabilities and treatment services forces people to travel long distances to get the services, reduce the hours of operation to daytime hours and can result in a loss of healthcare professionals due to a lack of satisfaction (working conditions, working environment, etc.) (World Health Organization, 2014).

Figure 6 presents the potential health benefits of community-wide electrification, taking into account the linkage between different sectors including health, education water and agriculture (Welland, 2017). It implies that electrification is the key for each sector and the

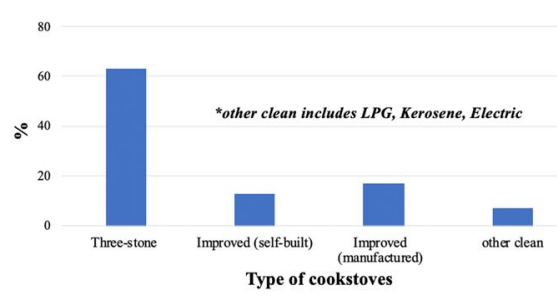

(a) Cooking technologies

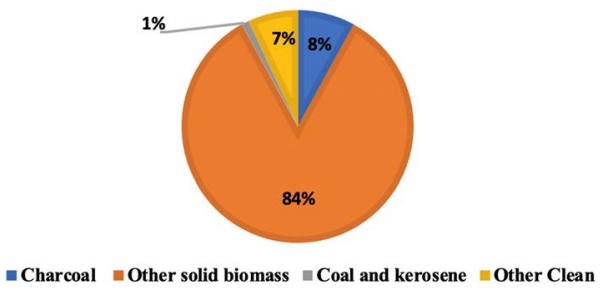

(b) Cooking fuels

Fig. 5 Ethiopia technologies (a) (Padam et al., 2018) and fuels (b) used for cooking (2018) (IEA, 2020a, 2020b, 2020c, 2020d, 2020e) 


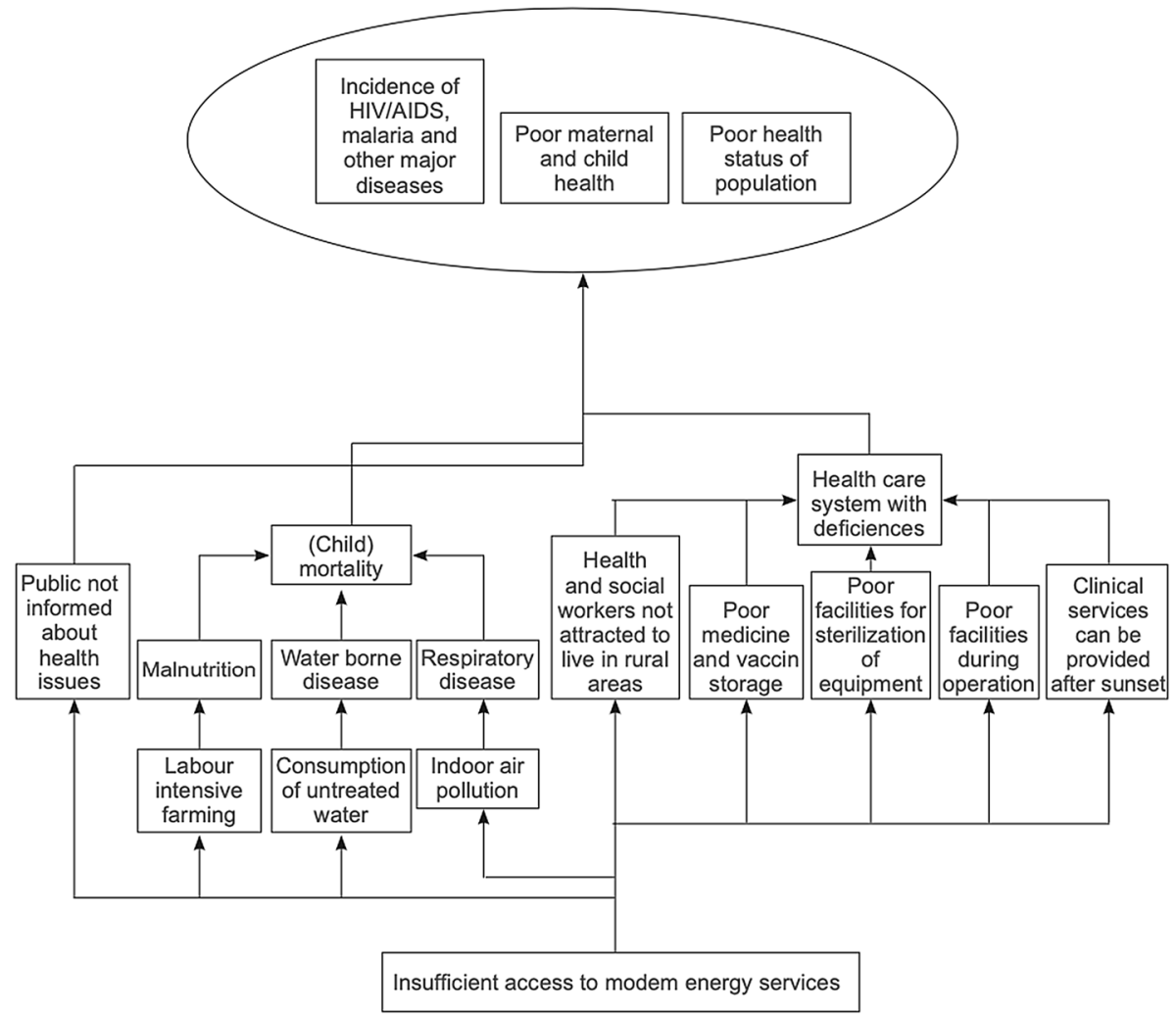

Fig. 6 Potential health benefits of community-wide electrification (Welland, 2017)

improvement of one sector can have a significant impact on another sector. For instance, access to electricity could increase the awareness of the society about health issues and what measures should be taken at the time of pandemic like COVID-19 using television, radio, or mobile phone through voice or text messages. The Ministry of Health of Ethiopia is using mobile calling to create awareness about the measures to prevent the spread of the coronavirus. For instance, one way of awareness creation is through ring tone (making the ringtone about how the virus is transmitted and what people should do to prevent the spread). However, people located in rural and remote areas could not benefit from it due to the lack of access to electricity, even if they have mobile phones they need to travel up to $5-25 \mathrm{~km}$ to charge the phone.

Based on the type of healthcare service they provide, the management and ownership style, location and patient capacity, the healthcare facilities can be divided into hospitals (large healthcare facilities), health centers (medium-sized facilities and health posts) (Andrea Franco, 2017). In Ethiopia, there are about 20,078 government-owned healthcare facilities from which the majority are health posts, i.e., 16,251. With regard to electricity access, as depicted in Fig. 7, about $90 \%$ of the facilities do not have access to electricity to any type of modern energy system, which implies about $70 \%$ of the hospitals have access to electricity followed by $28 \%$ of the health centers and $5 \%$ the health posts have access to electricity (MoWIE, 2019). 


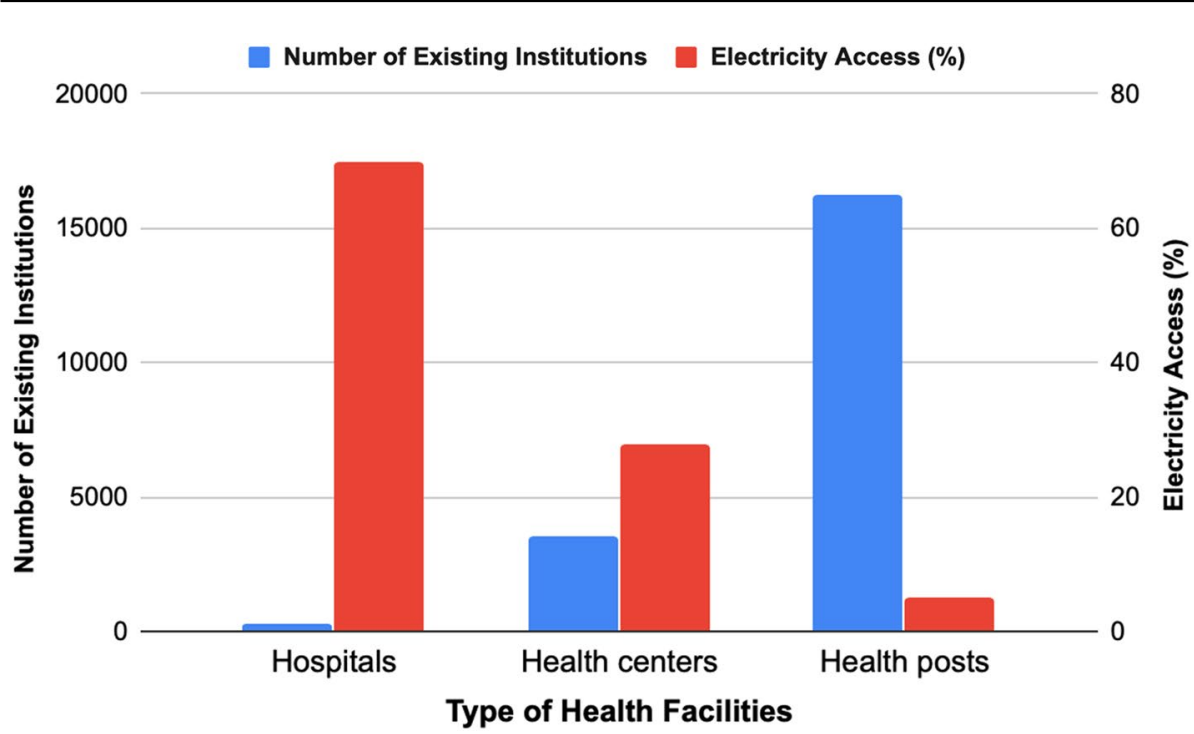

Fig. 7 Nation-wide access to reliable electricity services in health facilities ( Adapted from MoWIE, 2019)

For successful and healthy healthcare delivery as well as to have access and functional medical technologies, energy access is critical. Healthcare facilities in high-income countries like OCED member countries, struggle to provide necessary medical equipment and enough qualified human resources (Andrea Franco, 2017) to populations under growing strain from COVID-19, whereas in low-income countries like Ethiopia, healthcare facilities face the health crisis with the continuous and longstanding infrastructure and energy access challenges (Castán Broto, 2020). The number of infected people recorded in the third month onwards (from May 2020 to July 2020) and (February 2021 to April 2021) (Fig. 2) is a warning sign for the Ethiopian Health system and healthcare facilities. The issue is more alarming because most of the cases are recorded in vulnerable people (in low-income communities that live in congested areas and low-income means) as well as in the borders of Somalia and Sudan where the access to healthcare facilities and energy is very low.

\section{Discussion}

Reliable electricity access is essential to have high-quality healthcare services at every healthcare facility level, since most of the medical equipment needs electricity, the pharmaceutical products should be stored in freezers/refrigerators and the treatment of patients at night requires lighting. On the other hand, powering healthcare facilities is important to increase people's awareness about general preventive measures, increase the number of deliveries including live births and the number of medical interventions, decrease the rate of medical malpractice and accidents, minimize the average waiting time for emergency cases and outpatients, ensure equal and fair treatment of patients, ensure efficient communication and cooperation among healthcare facilities and to increase the number of patients treated per day and per health professional (WHO 2018). Therefore, powering healthcare 
facilities is critical to give effective, efficient, timeliness, community-centered, safe, equal and integrated healthcare services as shown in Fig. 8.

\subsection{Energy access, COVID-19 and healthcare services}

The above-mentioned benefits of powering healthcare facilities and performance indicators of high-quality healthcare services are more than ever very critical for an effective response to the COVID-19 pandemic. Furthermore, all the testing currently in use for active COVID-19 cases requires electricity (WHO, 2020a, 2020b). Patients in severe condition, need treatment with ventilators and/or oxygen masks in healthcare facilities that require a reliable power supply. Likewise, other services that are necessary for preventing the spread of the virus among patients and medical workers, such as cleaning equipment and sanitization including autoclaves and air treatment, controlled building ventilation and filtration as well as pumped clean water all require electricity (Fetter et al., 2020).

Without strict lockdown and few healthcare facilities (with very few ventilators), Ethiopia was not strongly affected by the pandemic till the end of May 2020 (Pilling, 2020), but the recent reports indicate that the numbers are increasing day by day in terms of new cases and death rates (Fig. 2). This implies that the country should increase the testing facilities in every corner of the country as well as prepare the hospitals with all necessary medical equipment for the response of the COVID-19.

However, as discussed in Sect. 3, most of the healthcare facilities do not have access to electricity and households also have a low rate of electricity access, in particular, in rural areas. This will make difficult the response for active infection cases in two aspects. The first one is the difficulty in installing testing facilities in rural and pre-urban places, due to the lack of access to electricity, which results in the samples being transported or people traveling to big cities and increasing the quantity of testing in one place, delaying the results. Due to this, the spread of the virus could increase since there are no strict lockdown or travel restrictions.

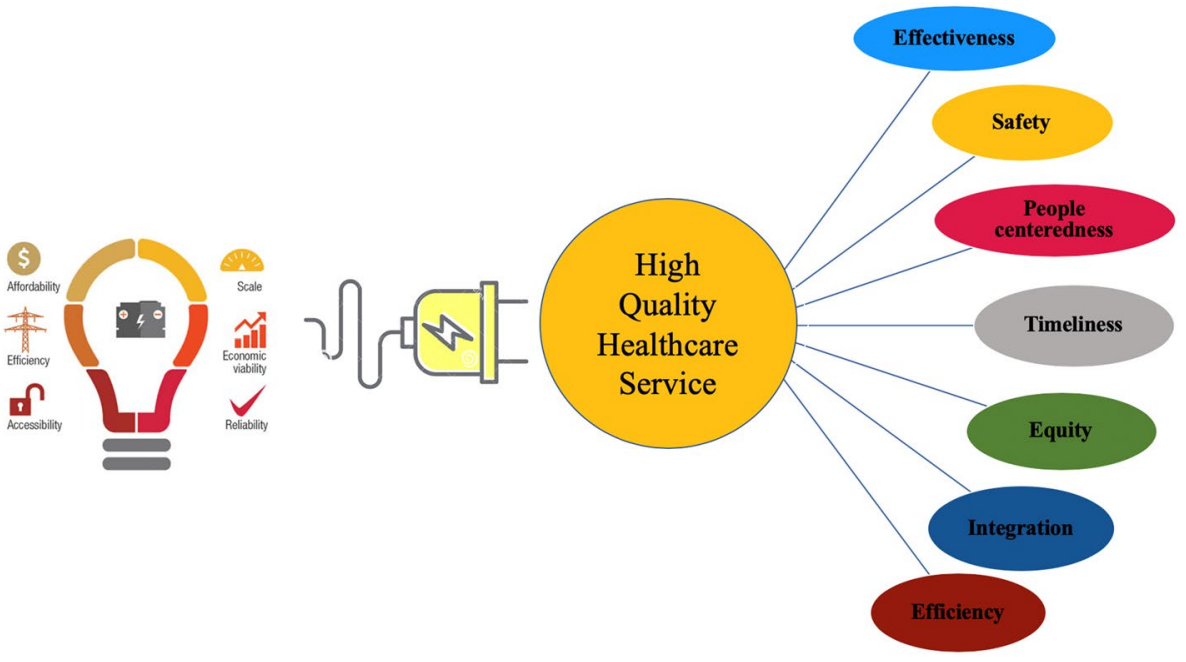

Fig. 8 Objective of powering health facilities and performance indicators (Adapted from WHO, 2018) 
Secondly, studies and reports indicate that healthcare facilities are already struggling with power outages. For instance, in St. Luke hospital located in Wolisso, $120 \mathrm{~km}$ southwest of the capital Addis Ababa, constant power outages risk patients' lives and damages medical equipment. To minimize the risk recently photovoltaic battery hybrid systems were installed (Enel Green power, 2019). Another study made in tuberculosis clinics in Southwest Ethiopia presented that TB diagnostic tests which took 2 days in a normal scenario took more than a week to process because of power outages so that the clinic staff was forced to refer patients to longer distant healthcare facilities (Dabaro, 2017). This situation will delay the COVID-19 test results and makes it difficult to take preventive measures as fast as possible (timely testing and information sharing are very critical for any outbreak) like putting suspected people in quarantine for longer periods or giving treatment for positive cases before it gets worsen.

Furthermore, for patients treated with ventilators or oxygen masks, even a few minutes of the power outage may be a life and death situation. The Minister of Health on June 11, 2020 stated that "Therefore, considering the amplified spread of the outbreak everyone should take extra precautions. Prevention is better than cure, staying home is better than being admitted to hospitals, and a face mask is better than a mechanical ventilator. Therefore, we should be alert and practice these and other precautionary measures to protect ourselves and loved ones from COVID-19" (Tadesse, 2020). In addition to the challenges with the access to energy services and low-quality healthcare systems, this statement from the Minister of Health is alarming, it implies that it is hard to trust the healthcare facilities due to the above-mentioned reasons and lack of enough resources for testing as well as for further treatment such as ventilators, oxygen mask, beds and lack of enough hospitals. Therefore, improving the power reliability (avoid power outages) in the healthcare facilities and testing centers and providing electricity access for healthcare facilities, for instance, in rural areas and borders is necessary to effectively combat the pandemic and control the outbreak before it is too late. Moreover, improving clean cooking access is also urgently necessary to minimize the respiratory complications and death risks of people infected by COVID-19.

\subsection{Post-COVID-19 and energy access}

The Ethiopian government universal energy access plan indicates that to achieve universal access by 2025, there is the need of investing about US\$ 6 billion in the grid and off-grid programs. The plan states that the investments will be covered by public, private sector and development partners. Out of the total, the government contribution is estimated to be about 25\% of the total investment (US\$ 1.5 billion) (MoWIE, 2019). However, this plan is at risk at the moment due to the economic crisis caused by the pandemic.

According to Ethiopian Economic Association (EEA, 2020), the GDP of Ethiopia will be reduced by $2.2 \%$ (US\$ 1.28 billion) in the best-case scenario (the assumption that the current shock will last for the 1st quarters of the new fiscal year 2020/21, July to September 2020/21) and $9.9 \%$ (US\$ 5.85 billion) in the worst-case scenario (assumes this shock will last up to the 3rd Quarter, January to March 2021). Whereas according to Alemayehu Geda (Professor of Economics at Addis Ababa University), the GDP of Ethiopia will shrink by $5.6 \%$ (US\$ 3.27 billion) in the best-case scenario and by $16.7 \%$ (US\$ 9.77 billion) in the worst-case scenario (Geda, 2020). In both studies, the GDP of the country will be affected by a high margin, which puts the government short of finance for new projects and investments. 
As the World Bank Group reported (Sánchez-Martín et al., 2020) and predicted by many researchers, (Angaw, 2021; Geda, 2020; Hirvonen, 2020) government and non-government organizations (Abdu, 2020; Abdu, 2020; Abdu, 2020; EEA, 2020; Fortune, 2020; Sozi, 2020), the Ethiopian economy declined since the country experienced the COVID-19 pandemic. For instance, the country has experienced a downfall in external demand since April 2020 due to COVID-19. The Ethiopian merchandise exports, except for gold. increased by $5.8 \%$ overall in the 2020 fiscal year, which declined by $4.1 \%$ during July-December 2020 (year-on-year). Since the pandemic, exports of garments, textiles, and fruits and vegetables have been particularly hit. Both exports and imports of services, dominated by air transport, recorded negative growth in the 2020 fiscal year. Even though it is regained in the first half of the 2021 fiscal year, remittances dropped by $10 \%$ in the 2020 fiscal year. Merchandise imports, which were already on the decline before COVID-19, dropped by $8 \%$ in the 2020 fiscal year, contributing to the narrowing of the current account balance, estimated at about $4 \%$ of GDP.

Meanwhile, foreign direct investment has been severely hit, with inflows declining by $20 \%$ in the 2020 fiscal year, contributing to weakening reserve levels. Despite the severe impacts, Ethiopia grew at $6.1 \%$ in the 2020 fiscal year, as the impact of the COVID-19 pandemic took place largely in the final quarter of the fiscal year. Some phone surveys made by the World bank group suggest that both firm revenue and household income are significantly depressed, which points to weakening domestic demand. Because of the low and regulation of the State of Emergency Proclamation, the number of workers fired remained low. While easing slightly during the first half of the 2021 fiscal year, at $19.2 \%$ in January 2021 inflation remained high, driven by high food prices (cereals and vegetables in particular). It is unclear whether the COVID-19 crisis has added to pre-existing inflationary trends. Recent surveys suggest the food security situation is not significantly worse than prior to the pandemic, at least in terms of food availability, although depressed incomes due to the crisis are likely to exacerbate the food affordability challenges the poorer households are facing. Furthermore, faster currency depreciation has only resulted in a reduction in overvaluation in recent months, as inflation started to ease. During the 2020 fiscal year, the birr depreciated by about $21 \%$ in nominal terms against the U.S. dollar (compared to $6 \%$ in previous years). However, by June 2020, the real effective exchange rate index (REERI) had appreciated by about $1 \%$ relative to June 2019 , due to the large inflation differential vis-à-vis trading partners. As inflation started to ease in the fall of 2020, it is estimated that the real exchange rate has been depreciating again during the first half of the 2021 fiscal year.

Among the new projects and investments, energy access projects include some implemented by the government contribution, which will be on hold due to the lack of financial resources. On the other hand, as per the funding plan in the universal energy access plan, about $75 \%$ of the costs are expected to be funded by the private sector and development partners as well as donors. Development partners like the World Bank (World Bank Group, 2019) and the African Development Bank are some of the donors that support Ethiopian clean energy projects for the last decade. Even at the time of the pandemic, the government gets a US\$ 10 million loan from the African Development Bank for the development of the 50 MW Tulu Moyo Geothermal Power Plant project (Africa Development Bank, 2020). Furthermore, there has been promising progress in clean energy technologies and sustainable energy access in Ethiopia and across developing countries.

The financial flows to developing countries indicate that about US\$ 18.6 billion in 2016 (which is almost 2 times as compared to the financial flow in 2010 (US\$ 9.9 billion) to support and promote clean and renewable energy systems (Castán Broto, 
2020). However, the global economic impact of the COVID-19 pandemic and the need for medical equipment supply at high demand is showing a blowing impact on energy systems around the world that will hugely affect the energy access plans of Ethiopia. According to the International Energy Agency, due to the contraction of oil, coal and gas markets, renewable energies are the only energy sources set for a growth in demand in the coming years and are the most resilient to COVID-19 lockdowns (Farand, 2020). However, recent market trends and reports indicate that renewables are also affected by the pandemic overall impact. In China, the impact of COVID-19 on renewables was evident mainly due to the delay in delivering equipment necessary for power plant construction. China is one of the countries which delivers most of the renewable power plant components including solar panels, wind turbines and batteries for the whole world. Nevertheless, since the spread of the COVID-19, orders have been delayed. As a result, renewable energy companies and distributors could not achieve the deadlines for the construction and installation of equipment (TETIANA MYLENKA, 2020). For example, in India, the delay of equipment supply and workforce availability resulted in about $63 \%$ of solar power plant projects being on hold because of the pandemic during the first 3 months of the year (GUPTA, 2020). On the other hand, a survey made by the global association for the off-grid solar energy sector (GOGLA) in March 2020 among its members found that due to the COVID-19 pandemic most of the members already faced serious challenges to operation and disruptions in sales as well as after-sales support. The study found that about $50 \%$ of off-grid companies could be in serious financial trouble if the pandemic lasts for more than 3-4 months, whereas about $11 \%$ of the GOGLA member off-grid companies found themselves in the immediate financial crisis (GOGLA, 2020).

Another survey study made by the Clean Cooking Alliance among different stakeholders in 100 countries on the impact of the COVID-19 pandemic on clean cooking presented that about $70 \%$ of the respondents found themselves in moderate or severe disruption to operations, while $21 \%$ are on the verge of ceasing operations. Moreover, cleaning cooking enterprises and NGOs are the ones largely impacted due to the crisis (Clean Cooking Alliance, 2020). Figure 9 presents the surveyed disruption results among stakeholders included in the study of the Alliance.

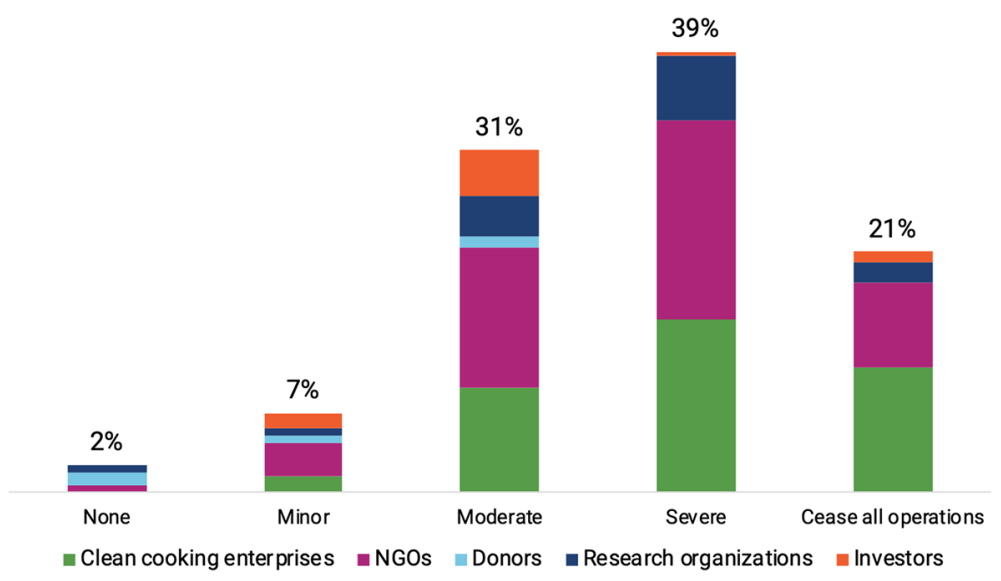

Fig. 9 Disruption due to COVID-19 for all respondents (CleanCookingAlliance, 2020) 
Ethiopia is one of the countries which has benefited from NGOs, donors, investors, off-grid companies and clean cooking enterprises. The crisis in these organizations will have a direct impact on the countries energy access at the moment as well as in its universal energy access plans. As discussed above, about $75 \%$ of the funds for universal energy access are expected from donors, the private sector, NGOs and development partners. The direct consequence of the pandemic on these organizations will limit the financial flows to Ethiopia for planned energy access projects, which will delay the start, completion and operations of planned power plant projects. On the other hand, Ethiopia's projects mainly depend on imported goods such as solar panels, batteries, wind turbines, materials required for exploration of geothermal energy, electromechanical equipment and turbines for hydroelectric power plants. Disruptions in the supply chain of these materials and equipment will hugely affect the power plant projects and will delay the installation, completion and operations of the projects as happened in India. For instance, the ministry of Water, Irrigation and Energy of Ethiopia said that the ongoing project of the Great Ethiopian Renaissance Dam (GERD) with a generation capacity of about 6.000 MW (US\$ 5 billion project) would be affected due to the delay of supply of electromechanical equipment and different materials for about 2 weeks to a month because of the disruption of the supply chain by the COVID-19 pandemic (Abdu, 2020). Furthermore, if the pandemic lasts for more than 3 months, millions of people will be at risk of looking for food and the number of people living in absolute poverty will be doubled from where it is now (Fig. 1). This could shift the focus of the government and the donors from development projects like energy access projects to humanitarian response and medical support that will largely impede the energy access situation and future universal energy access plans. (AfricaDevelopmentBank, 2020).

\section{Conclusions and policy response}

\subsection{Conclusions}

The paper aimed to assess the current status of energy access in sub-Saharan countries, in particular, in the healthcare facilities of Ethiopia as well as the impact of the pandemic during and post-COVID-19 pandemic on the universal energy access plans. It also intends to draw policy directions that could help the governments and other stakeholders on future measures for the improvement of energy access levels. The response to COVID-19 and the treatment of patients in intensive care is difficult due to the lack of access to electricity in the sub-Saharan countries and in healthcare facilities (in Ethiopia about $90 \%$ and in subSaharan Africa, about $72 \%$ do not have access to any means of modern energy services) as well as due to the frequent power outages. Additionally, the lack of energy access in the rural and pre-urban areas as a whole as well as in healthcare facilities can magnify the spread of the virus due to the lack of testing and treatment centers nearby. Another major issue that could magnify the complication and risk of death for the people infected by the virus is the lack of access to clean cooking options, due to the large impact on respiratory health. Furthermore, the economy will be hugely affected if the pandemic stays for more than 3-4 months, which will result in a shortage of financial resources for the universal energy access plan. Additionally, the global supply chain disruption and limitation of production due to COVID-19 lockdowns will result in the delay of supply of raw materials for installation, completion and operation of power plant projects already in construction or planned. This will strongly affect countries still with a low electricity access 
level. Therefore, the study analysis indicates that the impact of the COVID-19 pandemic in sub-Saharan countries' healthcare facilities and overall universal energy access plan is immense. Therefore, to minimize the impact, several short and long-term policy responses are proposed that should be implemented, including prioritizing powering healthcare facilities, distributing energy efficiency appliances and making sustainable energy access a central program for resilience and quick economic recovery. Moreover, attracting investors and private sectors to invest in resilient supply units could be the best option to avoid future supply chain disruptions. Furthermore, powering healthcare facilities with microgrids composed of solar panels and battery storage systems, since they are sustainable, safe and cost-effective, offers an immediate solution to power health facilities and communities in rural and pre-urban areas. Although it has been more than a year and a half since the pandemic outbreak, there are still people infected by the virus and the numbers are increasing, resulting in a worrying evolution of data and dynamic changes in the economy, health and social impacts, requiring urgent solutions, which is the limitation of the study. Therefore, the study needs further dynamic development by considering the day-to-day evolution of data and related policies to mitigate the impact of the pandemic in all round development plans of the country. Some short and long-term policy recommendations that should be undertaken to overcome the challenges of energy access and powering healthcare facilities are presented in the next section.

\subsection{Policy response}

Due to the pandemic, Ethiopia faced two main challenges in relation to energy access, namely:

1. Powering healthcare facilities in a short time for ensuring the speedy and effective response of the pandemic, through improved diagnosis and treatment and

2. The long-term impact of the pandemic on the universal energy access plan and ongoing projects.

These challenges require an immediate and long-term policy response to minimize the overall impact on socio-economic development and the quality of healthcare services.

\subsubsection{Short-term policy response}

As the number of infected people grows in the country, treating critical patients in hospitals, clinics and health posts that do not have access to electricity leads to risking human lives. When treatments are available in future, access to the vaccines will be a challenge for rural and pre-urban populations due to the lack of vaccine refrigeration facilities. Of course, the treatment of other diseases, requiring electricity for diagnosis and treatment as well as refrigeration, will also benefit from energy access. One solution would be the immediate and speedy deployment of off-grid power, such as minigrids for healthcare facilities whether it is located in rural or urban areas where energy access is limited. The importance of these deployed off-grid solutions is not only to ensure energy access for the healthcare facilities, but also can be used as a long-term sustainable energy service for the communities around. Therefore, the following policy responses are recommended to minimize the magnitude of the pandemic's impact on human lives due to lack of access to energy services: 
1. Prioritize powering healthcare facilities Governments of sub-Saharan countries, like Ethiopia, should prioritize powering healthcare facilities, in particular in rural and preurban areas which have to deal with emergencies and further patient treatment during the pandemic. Because of the shortage of funds, the Ethiopian Prime Minister asked Group 20 nations to cancel the debts for poor nations (Ahmed, 2020) like Ethiopia and also asked for further funds and loans to combat the pandemic. Likewise, governments should ask the international communities for support to power the health centers and first responders and the governments should also spend some funds on powering healthcare facilities. One cost-effective solution to ensure high-reliability energy services in health centers is microgrids supported by solar panels and battery storage. Therefore, the governments of sub-Saharan countries, should look at the option of using microgrids composed of solar panels and battery storage systems for healthcare facilities that do not have access to energy that could be crucial for the treatment of COVID-19. Sub-Saharan countries, like Ethiopia, are rich with solar radiation potential which is $5-6 \mathrm{kWh} / \mathrm{m}^{2}$ / day on average (solargis, 2019), which is a good opportunity to promote microgrids for sustainable cost-effective energy solutions.

2. Distribute energy-efficient solar lanterns, solar phone chargers and appliances (e.g., refrigerators and freezers) for vulnerable communities The Ministry of Health of Ethiopia is using mobile phones to receive information about the cases and to inform the population. However, most people in rural areas do not have access to any means of modern energy services to charge mobile phones. As a result, ensuring energy services for vulnerable communities through distributing energy efficient solar phone chargers, solar lanterns and appliances could be one of the measures that should be taken by the government as one of the priorities to keep connected the communities as well as preventive measures to avoid the spread of the virus. Energy efficiency measures and promoting energy-efficient appliances are also important measures for pre-urban and urban areas to advance energy access.

3. Avoid power outages and interruption of generation Power outages are a bottleneck for many industries, households and service centers in the country. On average, $60 \%$ of the consumers face power interruption four times per week (Day, 2020). For patients in intensive care, power interruption means a life-threatening situation, since keeping ventilators and oxygen masks on, cleaning and sterilizing different medical equipment are necessary, that could be impossible if power outages happen every time. Therefore, the government should take steps to avoid power outages, in particular in hospitals, testing centers and special COIV-19 treatment centers. Microgrids supported by solar panels and battery storage systems could be used as a backup in healthcare facilities and households located in urban and rural areas to ensure high reliable energy services and avoid risk due to power outages, since they are cost-effective and sustainable. On the other hand, the industries should continue the production and delivery of goods and services for the local and international markets. This should not be affected due to poor management of power grids and frequent power outages.

\subsubsection{Long-term policy response}

As a long-term policy, governments of sub-Saharan countries should take sustainable, reliable, affordable and sufficient access to energy services as a core strategy for increasing healthcare resilience and providing better healthcare service as well as to ensure fast economic recovery. Therefore, the governments should work tirelessly to complete the projects 
already started like GERD and mobilize donors, private sectors and investors for off-grid solution deployment at a large scale for rural and pre-urban areas. Furthermore, the government should attract investors to set up manufacturing industries for renewable energy components such as solar panel manufacturing and assembly industry, wind turbines manufacturing and assembly industries and other components manufacturing units. This will avoid future disruption of the supply chain and help for the successful completion of power plant projects as planned, as well as it will support the economy by creating jobs and exporting products for neighboring countries. On the other hand, the governments should also give special attention to the energy efficiency policy development and implementation as well as on the adoption and promotion of energy-efficient appliances like clean cooking technologies and fuels.

\section{References}

Abdu, B. (2020). https://www.thereporterethiopia.com/article/covid-19-delays-gerd-material-delivery. Retrieved June 2020.

AfricaDevelopmentBank. (2020). https://www.afdb.org/en/news-and-events/press-releases/african-devel opment-bank-welcomes-10-million-clean-technology-fund-investment-diversify-ethiopias-energymix-35569. Retrieved June 2020.

Ahmed, A. (2020). https://www.nytimes.com/2020/04/30/opinion/coronavirus-debt-africa.html. Retrieved June 2020.

Alemu, G. T. (2020). https://addisstandard.com/economic-analysis-covid\%e3\%83\%bc19s-test-to-the-ethio pian-economy/. Retrieved June 2020.

Andrea Franco, M. S. (2017). A review of sustainable energy access and technologies for healthcare facilities in the Global South. Sustainable Energy Technologies and Assessments, 22, 92-105.

Angaw, K. W. (2021). Policy responses and social solidarity imperatives to respond the COVID-19 pandemic socioeconomic crises in Ethiopia. ClinicoEconomics and Outcomes Research, 13, 279-287.

Besha, A., Tsehaye, M., Tiruye, G., Gebreyohannes, A., Awoke, A., \& Tufa, R. (2020). Deployable membrane-based energy technologies: The Ethiopian prospect. Sustainability, 12, 8792.

Beyene, G., Kumie, A., Edwards, R., \& Troncoso, K. (2018). Opportunities for transition to clean household energy in Ethiopia: Application of the household energy assessment rapid tool (HEART). WHO.

Beyene, G. K. (2018). Opportunities for transition to clean household energy in Ethiopia: Application of the household energy assessment rapid tool (HEART). World Health Organization. https://apps.who.int/ iris/handle/10665/311280. License: CC BY-NC-SA 3.0 IGO.

Carrington, D. (2020). https://www.theguardian.com/environment/2020/apr/07/air-pollution-linked-to-farhigher-covid-19-death-rates-study-finds. Retrieved June 2020.

Cassia, R., Nocioni, M., Correa-Aragunde, N., \& Lamattina, L. (2018). Climate change and the impact of greenhouse gasses: $\mathrm{CO}_{2}$ and $\mathrm{NO}$, friends and foes of plant oxidative stress. Frontiers in Plant Science, 9, 273.

Castán Broto, V. K. (2020). Energy access is needed to maintain health during pandemics. Nature Energy, $5,419-421$.

CleanCookingAlliance. (2020). A survey from the Clean Cooking Alliance reveals how COVID-19 is impacting the clean cooking sector.

Dabaro, D. (2017). Factors affecting tuberculosis case detection in Kersa District, South West Ethiopia. Journal of Clinical Tuberculosis and Other Mycobacterial Diseases, 9, 1-4.

Day, E. (2020). EEG energy insight: Moving beyond energy access-The challenge and impact of unreliable electricity in emerging economies. Applied Research Programme on Energy and Economic Growth.

Edoardo Conticini, B. F. (2020). Can atmospheric pollution be considered a co-factor in extremely high level of SARS-CoV-2 lethality in Northern Italy? Environmental Pollution, 261, 114465.

EEA. (2020). Economic and welfare effects of COVID-19 and responses in Ethiopia: Initial insights, Ethiopian Economic Association (Unprocessed). Ethiopian Economic Association, EEA.

EnelGreenpower. (2019). https://www.enelgreenpower.com/stories/articles/2019/03/photovoltaic-batteryhybrid-system-st-luke-hostpital-ethiopia. Retrieved 2020 June.

Farand, C. (2020). https://www.climatechangenews.com/2020/04/30/renewables-resilient-covid-19-lockd own-measures-says-iea/. Retrieved June 2020. 
Fetter, R., Fuller, A., Porcaro, J., \& Sinai, C. (2020). https://www.brookings.edu/blog/future-devel opment/2020/06/05/you-cant-fight-pandemics-without-power-electric-power/?preview_id=82487 2\&fbclid=IwAR00-29ujA1NVBJpnpCy4adNr7cBWxn-MalaA2w1U-6FUf565GFPBHVKx 10. Retrieved June 2020.

Fortune, A. (2020). Cost of vegetables, cereals increase as inflation creeps higher. Addis Fortune.

Gautam, S. H. (2020). COVID-19: Impact by and on the environment, health and economy. Environment, Development and Sustainability, 22, 4953-4954. https://doi.org/10.1007/s10668-020-00818-7

Geda, A. (2020). The macroeconomic and social impact of COVID-19 in Ethiopia and suggested directions for policy response (unprocessed).

GOGLA. (2020). COVID-19: Coordinating an industry response for the off-grid solar sector.

Gupta, U. (2020). https://www.pv-magazine-india.com/2020/06/02/covid-cuts-indias-utility-scale-solaraddition-by-63-in-first-quarter/. Retrieved June 2020.

Hirvonen, K. (2020). Economic impacts of COVID-19 pandemic in Ethiopia: A review of phone survey evidence. IFPRI-strategy support program I working paper 151.

IEA. (2020a). Ethiopia fuels and technologies used for cooking by scenario, 2018-2030. IEA. https:// www.iea.org/data-and-statistics/charts/ethiopia-fuels-and-technologies-used-for-cooking-by-scena rio-2018-2030.

IEA. (2020b). https://www.iea.org/reports/sustainable-recovery/covid-19-and-energy-setting-the-scene\# abstract. Retrieved June 2020.

IEA. (2020c). Key world energy statistics.

IEA. (2020d). Key world energy statistics. Available online: https://www.iea.org/reports/key-worldenergy-statistics-2020.

IEA. (2020e). Sustainable recovery: World Energy outlook special report.

Issa, M. (2016). Energy report-Ethiopia. Embassy of Sweden.

Kammila, S., Kappen, J. F., Rysankova, D., Hyseni, B., \& Putti, V. R. (2014). Clean and improved cooking in Sub-Saharan Africa: A landscape report (English). World Bank Group. http://documents. worldbank.org/curated/en/164241468178757464/Clean-and-improved-cooking-in-Sub-SaharanAfrica-a-landscape-report.

Leal Filho, W., Brandli, L., Lange Salvia, A., Rayman-Bacchus, L., \& Platje, J. (2020). COVID-19 and the UN sustainable development goals: Threat to solidarity or an opportunity? Sustainability, $2020(12), 5343$.

MoWIE. (2019). National electrification program 2.0: Integrated planning for universal access. Ministry of Water, Irrigation and Energy of Ethiopia.

Muhammad Yousaf Razaa, X. W. (2021). Economic progress with better technology, energy security, and ecological sustainability in Pakistan. Sustainable Energy Technologies and Assessments, 44, 100966.

Mulugeta, M., \& Jalata, G. G. (2020). The impact of COVID-19 pandemic on food security in Ethiopia (unprocessed).

Ourworldindata. (2020). https://ourworldindata.org/grapher/per-capita-electricity-consumption. Retrieved July 2021.

Padam, G., Rysankova, D., Portale, E., Koo, B. B., Keller, S., \& Fleurantin, G. (2018). EthiopiaBeyond connections: Energy access diagnostic report based on the multi-tier framework. World Bank. https://openknowledge.worldbank.org/handle/10986/30102 License: CC BY 3.0 IGO.

Pilling, D. (2020). https://www.ft.com/content/7c6327ca-a00b-11ea-b65d-489c67b0d85d?fbclid=IwAR1 ogmFZcFFw9JXu8kE_wW8MOE6-9RkC64r3HtBAvrIphxJZle4qLcr5AmA. Retrieved June 2020.

Raza, M. S. (2020). Analysis of coal-related energy consumption in Pakistan: An alternative energy resource to fuel economic development. Environment, Development and Sustainability, 22, 6149-6170.

Sánchez-Martín, M., Mulugeta, S., Getachew, Z., \& Wieser, C. (2020). Ensuring resilient recovery from Covid-19. Ethiopia Economic Update (Vol. 8). World Bank Group.

solargis. (2019). https://solargis.com/maps-and-gis-data/download/ethiopia. Retrieved June 2020.

Sozi, C. (2020). Socio-economic impact of COVID-19 in Ethiopia. United Nations Ethiopia.

Tadesse, L. (2020). https://twitter.com/lia_tadesse/status/1271047898642419713/photo/3. Retrieved June 2020.

TETIANA MYLENKA, L. C. (2020). https://www.pv-magazine.com/2020/04/24/impact-of-covid-19on-the-global-energy-sector/. Retrieved June 2020.

The Macroeconomic and Social Impact of COVID-19 in Ethiopia and Suggested Directions for Policy Response. (2020). Alemayehu Geda.

Wazemaradio. (2020). https://www.pv-magazine-india.com/2020/06/02/covid-cuts-indias-utility-scalesolar-addition-by-63-in-first-quarter/. Retrieved May 2020, 
Welland, A. (2017). Electrification of health clinics in rural areas: Challenges and opportunities. CMEDT Smart Villages Initiative, c/o Trinity College, Cambridge

WHO. (2020a). https://www.who.int/emergencies/diseases/novel-coronavirus-2019/advice-for-public. Retrieved June 2020.

WHO. (2020b). https://www.who.int/publications/i/item/advice-on-the-use-of-point-of-care-immunodiag nostic-tests-for-covid-19-scientific-brief. Retrieved June 2020.

WHO, W. B. (2018). Delivering quality health services: A global imperative for universal health coverage. WHO.

World Health Organization, W. B. (2014). Access to modern energy services for health facilities in resourceconstrained settings: A review of status, significance, challenges and measurement. Reprinted in 2015 with changes: https://apps.who.int/iris/handle/10665/156847. World Health Organization.

WorldBankGroup. (2019). https://www.worldbank.org/en/news/press-release/2019/05/23/world-bankgroup-supports-ethiopia-in-providing-reliable-energy-and-creating-opportunities-for-private-inves tment-in-the-sector. Retrieved June 2020.

Worldometers. (2020). https://www.worldometers.info/world-population/ethiopia-population/. Retrieved May 2020.

Publisher's Note Springer Nature remains neutral with regard to jurisdictional claims in published maps and institutional affiliations. 